\title{
Psicología del ateísmo occidental
}

\section{Ricardo Antonio Villalobos Paniagua}

Magíster en Educación con énfasis en Docencia Universitaria y licenciado en Filosofía por la Universidad Nacional, licenciado en Ciencias de la Educación con énfasis en Docencia de la Filosofía y las Humanidades por la Universidad Estatal a Distancia, y bachiller en Filosofía y Humanidades por la Universidad Católica de Costa Rica. Profesor en la Escuela de Estudios Generales de la Universidad de Costa Rica (sección de Filosofía y Pensamiento), tutor de la UNED en las cátedras de Filosofía y Métodos de Investigación y Estudio a Distancia y profesor en la Universidad Nacional (CIDE). Correo electrónico: ravp1970@yahoo.com

Recibido: Setiembre 2013 • Aceptado: Marzo 2014

\section{RESUMEN}

El siguiente artículo ensayo tiene como cometido la reflexión, nuevamente, de un tema del orden filosófico y que en cuanto metafísico le compete. No es un discurso apologético del cristianismo, aunque lo parezca, sino un análisis al ateísmo de su conciencia de ser. En cuanto al cristianismo, ese será un nuevo asunto por discutir próximamente. Ateísmo, tan atractivo como el cristianismo mismo y en Occidente tan hermanado con este, como Caín y Abel.

Palabras clave: ateísmo, psicología, filosofía, cristianismo.

\section{ABSTRACT}

The following article essay is focused on the reflection, again, a subject of philosophical and metaphysical as it is responsible. It is not an apologetic discourse of Christianity, despite appearances, but an analysis of his atheism awareness. As for Christianity, this will be a new issue to be discussed soon. Atheism, as attractive as Christianity itself and as brothers in the West as Cain and Abel.

Key words: atheism, psychology, philosophy, Christianity.

\section{Introducción}

Este breve ensayo no busca explicar a fondo el pensamiento de los filósofos ateos citados, sino que, a partir de ellos, y con el fundamento de la reflexión de otros pensadores y del autor de este artículo, generar un sintético análisis del problema planteado.

El ateísmo es parte esencial del discurso filosófico, pues uno de sus tres "problemas fundamentales" es la discusión acerca de la posible existencia de Dios (los otros dos son el ser humano y la naturaleza, o mundo). Aunque muchos podrían considerar que el filósofo por antonomasia es ateo, esto en realidad es falso, porque él también se permite creer y filosofar acerca del misterio de la divinidad, lo que es muy común. Bien Miguel de Unamuno repetía: "No creer es creer".

Este artículo está dirigido a partir de una concatenación argumentativa desde lo que denominaremos "enclaves", momentos retóricos y reflexivos que invitan a la disposición para determinar nuevas reflexiones.

Así, este documento es una exposición que parte de un principio filosófico básico: la 
posibilidad de expresarse, la posibilidad de manifestar un discurso que no es ideología.

\section{Primer enclave: jantropomorfización de Dios!}

La duda no solamente es de carácter natural humano, sino epistemológicamente filosófico, y si el filosofar es también natural e intrínseco al ser humano, dudar es válido y pertinente. La duda epistemológica nos provee de posibilidad de conocimiento, $\mathrm{y}$ de adquirirlo satisfactoriamente $-\mathrm{O}$ al menos momentáneamente, que no siendo lo definitivo- nos permite alcanzar un "algo más" en su búsqueda y adquisición.

Y si bien dicha satisfacción es momentánea -no obviemos que Schopenhauer tenía razón con su idea de que la insatisfacción en el ser humano es permanente- no podemos disimular la dicha que nos brinda el adquirir conocimiento, una invitación por sí a querer y a desear más saber.

El sentido de la existencia del filósofo es esto: adquirir verdad, adquirir conocimiento: la filosofía es incansable búsqueda de verdades, y de la Verdad.

No considero bien referirme al mal utilizado concepto de "verdades relativas", tan posmodernista como tan irreconciliable con la razón, sino de "verdades", porque se nos permiten, mediante la ciencia y la filosofía, para así caminar en la cognición del mundo y de nosotros mismos. Si verdades no hubiesen, vano sería nuestro filosofar, y si el discurso - de por si absurdo y necionos dice que "la verdad es relativa", dejemos de educarnos y de asistir a los centros de estudios, como de creer en nosotros mismos y de aducir, como el escéptico, que "todo es relativo".

Sin el concepto de "verdad" la ciencia, la filosofía y todo posible conocimiento de la humanidad es absurdo, y por ende la humanidad sería también un completo absurdo.

Ciertamente el concepto de "verdad relativa" no es más que una dependencia del concepto "doxa" (opinión); sin embargo, la "episteme" (ciencia) nos insta a pensar en verdades absolutas, o en "verdades perfeccionadas" en tanto búsqueda de "la Verdad".

$\mathrm{Y}$ es que no podemos negar que -absolutamente- estoy escribiendo y pensando esto, iy lo hago yo, no otro!, por lo tanto no trata de una verdad relativa, sino absoluta.

La Verdad es absoluta porque es indudable. Las verdades son perfeccionadas porque son conocimientos que generan teorías que van a producir otras nuevas teorías. La "verdad relativa" es opinión, es perspectiva, es interpretación.

La Verdad Absoluta, en tanto búsqueda incluso desde las opiniones personales, es real y evidente, por lo tanto es verdadera. Somos seres individuales y sociales, la verdad personal es opinión (doxa), la verdad social tiende a la Verdad Absoluta (episteme=ciencia). La verdad personal se suma a la Verdad Histórica, que está agregada a la Verdad Absoluta, es decir, a lo indudable. Y es indudable que estás leyendo lo que yo indudablemente he escrito acá, que quizás me comprendas o no, o que puedas estar de acuerdo con mi tesis o no estarlo.

Tanto la ley como la cultura son contextuales y circunstanciales, son sociales, pero son de absoluta incumbencia de todos en su contexto histórico y social. La opinión personal que no reflexiona tiende a hacernos creer que no hay verdades absolutas, porque dicha opinión está enmarcada en la naturaleza arrogante e individualista del ser humano, muy bien acuñada y alimentada por nuestra época "posmoderna". Y no es que la verdad sea contextualizada, la Verdad es universal; contextualizada es la opinión, personal o comunal.

Vivimos en una historia actual del relativismo y del nihilismo, una negación de la Verdad. Se repite el absurdo epistemológico escéptico. Cuándo habremos de entender que la Verdad Absoluta es evidente, de hecho es el camino científico de la humanidad.

Por ello, debido a todo este disgusto actual -promovido por un posmodernismo antirreligioso- he decidido retomar un tema permanente en la historia filosófica y occidental, un tema que no pierde vigencia: el ateísmo, enfocado en esta oportunidad con un interés psicológico.

El disgusto del ser humano con el concepto "Dios" y el cuestionamiento de su existencia se justifican por tanto mal en el mundo y por 
tanto egocentrismo humano. Un solo vistazo a la humanidad nos explicarían el porqué de tal desencanto.

Psicológicamente Dios sería, para el ateo, algo así como un trauma, una situación relevante a la negación por cuanto causa disgusto e incluso resentimiento, por lo cual el ateo merece intervención psicoanalítica. Súmese a esta condición, que el ser humano -histórica y naturalmente- desea autogobernarse (por eso la ultradefensa de la democracia), y Dios resulta ser una máxima autoridad, lo que motiva el disgusto.

El ateísmo es la conciencia psicológica del ser humano que busca negarse a creer en el bien y se imbuye en creer en el absurdo de la existencia, con negatividad y un pesimismo absoluto.

Hay un disgusto moral contra los conceptos de bien y de mal, y contra el concepto de ética y de pecado, fundamentados por una historia social actual inclinada cada vez más hacia el egoísmo y el individualismo.

La "muerte de Dios" (Nietzsche) se convirtió en la expresión máxima contemporánea de ese disgusto humano: su estandarte, la búsqueda del desarraigo feliz de quien nos aprisiona y nos posee y nos hace creer que hay un bien y que hay seres humanos buenos. Es la noticia de la redención histórica de la pesadumbre y el pesimismo en su máxima expresión. Pero no solamente es liberarse, sino ante todo negarse a creer en el bien, y por lo tanto, sujetarse al resentimiento. Y con esto el ateo acude a "su verdad" y esta es absoluta para él.

¿Será que al ateo le causa temor Dios? Afirmarlo significaría que está errado, y nadie quiere errar. ¿Será porque se da cuenta de que su discurso anarquista se funda en Dios, y sin Dios su discurso, y en total su ontología, serían "nada"?

"El ateísmo, pues, aparece, como una situación explicable de un olvido posible de Dios, ahondado y agravado este olvido por la presencia impresionante de lo que no es Dios" (Muñoz, 1972: 124). El centro de nuestra discusión intenta establecer que el ser humano ha antropomorfizado a Dios, y la antropomorfización de Dios es quizás el más grave delito religioso. Y el ateísmo -en tanto es él mismo una religión- lleva a traducir, a interpretar y a explicar al incognoscible y misterioso Dios, y con esto tiende a determinar lo que Dios no es, por ende, Dios tiende, religiosamente, a ser lo que el ser humano quiere que sea, tal es el absurdo que hemos querido señalar.

Filosóficamente, la postura más sensata ante el Misterio Dios no está en afirmarlo o negarlo o simplemente en producir hipótesis sobre una postura u otra. El dilema es que la religión ha aceptado la acción de Dios pero lo ha antropomorfizado, lo cual ha sido muy dañino en la historia. El delito religioso lo comete el filósofo ateo también, aunque esto parezca irrisorio, porque también antropomorfiza a Dios, lo "ve" como hombre.

El delito filosófico, al respecto, está en que el filósofo ateo se queja en un campo que no es el suyo -y que muy probablemente no conoce, pero que critica y odia-, el campo de la fe, el metafísico; pero el ateo también es una persona de fe: "Cada ateo no niega a Dios, sino que cada ateo niega a su Dios... el ateo más que negar a Dios lo que consigue es negarse él para Dios" (Muñoz, 1972: 128).

El ateísmo se convierte en una religión de la negación, en una dialéctica de la no aceptación de Dios, pero que a la vez afirma aquello que rotundamente quiere impedir como real hasta la burla. Sciacca escribe: "el ateísmo, bajo cualquier forma que se presente, no es racional porque es intrínsecamente contradictorio y una violencia del hombre a su propia naturaleza”(1963: 195). ¡Al negar a Dios se piensa en Dios!

\section{Segundo enclave: el ateísmo en la contemporaneidad}

El ateísmo es pragmático, como pragmático es el posmodernismo y su nihilismo, su egocentrismo y su iconoclasia. El ateísmo teórico de los grandes pensadores ateos recientes -desde el interés de Ludwig Feuerbach hasta el de Jean Paul Sartre- por buscarle un fundamento racional se convirtió en un interés irracional, emocional y sentimental. $\mathrm{Si}$ alguien quiere, puede creer en la existencia de Dios o no hacerlo, lo cual es un 
asunto de fe, y la fe es irracional, y el ateo también tiene fe.

Dios se ha convertido en un "evento" epistemológico, cuando debería analizarse como un "evento" ontológico.

El ateo clásico afirma una negación, jeste es su error!, pero a la vez su dialéctica se descubre en realidad en el campo del enfrentamiento antropológico: se intuye más un enojo con el ser humano y sus acciones que con una entidad metafísica (pues hasta niega su existencia). $\mathrm{Su}$ disgusto es por lo humano, que se transforma en un disgusto antropomórfico elevado a lo ideal, por cuanto no es posible decir mucho o nada de Dios. El disgusto ateo es hacia esas actitudes humanas que quiere ver en lo incognoscible, en Dios. También en el ateísmo se da una insatisfacción schopenhaueriana.

Es imposible e irrisoria una lucha contra Dios para negarlo. La lucha en realidad es contra la humanidad que se ha representado en la imagen de la divinidad. En concreto, la lucha es contra la religión y lo religioso, no contra un Dios, aunque se empeñe en continuar afirmando y defendiendo lo contrario.

El ateísmo posmoderno -que en su origen es iconoclasta, una simple y llana negación de la ley- no es sino un movimiento que produjo en la historia maneras de pensar pseudoanarquistas, pro defensa de derechos irracionales. El absurdo es mayor cuando, evidentemente, se descubre como rasgo "filosófico" del posmodernismo lo irracional (entiéndase lo sentimental y lo sensual). Estamos en la época de lo irracional, por eso el ateísmo es irracional esencialmente.

Si bien es cierta la invitación epistemológica respecto de Dios, y es justo movernos entre las ideas de la posibilidad o la imposibilidad de su existencia, no olvidemos que la presentación que de Dios hacen las religiones y sectas consiste en absolutizar su existencia, tanto epistemológica como ontológicamente, lo cual genera choque con el nihilismo posmoderno, porque ambas tendencias absolutizan sus teorías, y por ende se enojan una con la otra.
El siglo XIX nos legó a Friedrich Nietzsche, aquel alemán extraordinario, irreverente, muy loco, admirado y odiado, acicate de los posmodernos y del nazismo, en cuyas ideas estos se hacen un nudo y no se sueltan. Peligroso, muy peligroso. El pensamiento posmoderno se puede resumir en las siguientes tesis:

1. La defensa extrema de sus tesis neoliberales: libertad sexual, antimoral, antirreligión, antifilosofía, anticiencia; nihilismo absoluto traducido a neoescepticismo.

2. Una sociedad hedonista, egocéntrica, centric corpus (narcisista).

3. Desprecio por los dogmas y por los conceptos de "verdad absoluta" y de objetividad.

4. Negación de toda autoridad, en defensa de un pseudodiscurso de libertad individual.

5. Defensa del pseudodiscurso que considera construidos socialmente los conceptos de bien y de mal.

6. Negación del concepto de "naturaleza".

7. Terror a lo metafísico.

8. Advenimiento de la "cultura de masas".

9. Defensa del "laissez faire, laisser passer" y del "prohibido prohibir".

El ateísmo, alimentado por el posmodernismo, adviene irreverente y violento. $Y$ una consecuencia psicológica de ese posmodernismo es la defensa consciente e inconsciente de los intereses propios.

Aunque no se puede negar que en la religión también se da la defensa de intereses propios (y por qué no, también egocéntrica e individualmente), por ello también ambos, ateísmo y religión mantienen una psicología ontológica semejante: deseos de poder.

En fin, parece que no logramos entrever una distinción entre religión y ateísmo, y ambas parecen confundirse en la misma razón de ser: la defensa de sus propios intereses. Y ¿por qué no?, si el ser humano es egoísta por naturaleza. 
Para el posmodernismo la religión y Dios son y se convierten en obstáculos y enemigos de la libertad. Para el posmodernismo todo concepto de autoridad coarta la libertad e identidad y nos confunde en la alienación. El objetivo psicológico es simple: ¡absoluta libertad!

\section{Tercer enclave: el ateísmo como enfrentamiento a la religión}

La psicología del ateísmo se relaciona, para nuestros efectos, funcional y consecuentemente con la psicología de la religión.

La religión, psíquicamente, no es sino el resultado del necesario anhelo de inmortalidad o eternidad del ser humano, el cual nace para vivir y quiere, desea, seguir viviendo, por eso la muerte tiende a aterrarle, y el terror es mayor cuando descubre que en realidad está muriendo y no viviendo. Unamuno escribió:

$Y$ vuelven a molernos los oídos con el estribillo aquel de jorgullo!, ;hediondo orgullo! ¿orgullo querer dejar nombre imborrable? ¿Orgullo? Es como cuando se habla de sed de placeres, interpretando así la sed de riquezas. No, no es tanta ansia de procurarse placeres cuanto el terror a la pobreza lo que nos arrastra a los pobres hombres a buscar el dinero, como no era el deseo de gloria, sino el terror al infierno lo que arrastraba a los hombres en la Edad Media al claustro con su acedía. Ni esto es orgullo, sino terror a la nada. Tendemos a serlo todo, por ver en ello el único remedio para no reducirnos a nada. Queremos salvar nuestra memoria, siquiera nuestra memoria. ¿Cuánto durará? A lo sumo lo que durase el linaje humano. ¿Y si salváramos nuestra memoria en Dios? (2004: 86-87)

El terror a la nada parece sostener, psicológicamente, a la religión, por ende esta es una esperanza de supervivencia, tal como el instinto humano siempre lo ha propuesto.

En el ateísmo ¿qué sostén psicológico existe? Parece ser que únicamente el de la autodeterminación y la autosuficiencia absolutas; pero como Dios y la religión -consideran los ateos-quitan la libertad, el camino por seguir es enfrentarlos en una guerra a campo abierto.
Es el miedo a la extinción lo que nos lleva a la religión y el miedo a la esclavitud la que nos lleva al ateísmo. En fin, en ambas lo que influye es el miedo a la nada.

Ante la realidad de que por naturaleza somos seres religiosos tanto como sociales y racionales es que se convalida la discusión de aceptación de la existencia de Dios o su inexistencia. Es intrínseca a nosotros esta dialéctica. Y en esta disputa, ¿quién tendrá la razón: ateos o teístas? Enorme dilema. Buscamos la razón de una posibilidad o no posibilidad, y la respuesta ha de venir desde lo racional, y este es justamente un gran problema, pues parece que tanto religión como ateísmo se dirigen más -en sus apologías epistemológicaspor la emoción y lo irracional. Pero la razón sí dice algo: ¡Dios es un misterio! ¡La existencia de Dios es un misterio!

Otro gran dilema es que el concepto Dios es plural, entiéndase, que no existe un solo concepto, aunque debe ser Uno solo, porque cada uno de nosotros en su individualidad tiene su particular idea de Dios, no solo una idea social. Escribe Unamuno: "No creo que sea violentar la verdad el decir que el sentimiento religioso es sentimiento de la divinidad y que solo con violencia del corriente lenguaje humano puede hablarse de religión atea. Aunque es claro que todo dependerá del concepto que de Dios nos formemos. Concepto que depende a su vez del de divinidad"(2004: 189).

El ateísmo rehúsa la actitud religiosa, aunque en realidad la aplica, pero ¿por qué? Los motivos son de carácter psicológico e ideológico. Porque busca imponerse. Se justifica por "su razón", o doxa, aquella misma de Feuerbach, para quien la teología no es sino una antropología: Dios como proyección del hombre. En Nietzsche hallamos la celebérrima frase: "Dios ha muerto". En Así hablaba Zaratustra, la expone desde un inicio: Cuando Zaratustra estaba de nuevo solo, dijo para sus adentros: “¿Será posible? ¡Ese viejo santo en su bosque no se ha enterado aún de que Dios ha muerto!'(2002: 9). Recordemos que Nietzsche es la fuente del ateísmo más radical y posmodernista. 
La influencia filosófica de Feuerbach en Nietzsche es real y evidente. La psicología atea, de ellos por lo tanto, se funda en considerar, y criticar fuertemente, a la religión como manipuladora del discurso de lo que es bueno y de lo que es malo, es decir, de la moral. Para el ateo, en general, la religión, desde su enraizamiento original en el concepto de pecado deja de creer en el mundo terrenal, y con ello se desinteresa de este, lo abandona irresponsablemente pensando y dejándose llevar por la idea ilusoria de un Cielo. Nietzsche, "quien va más allá del bien y del mal", dice: "Amo a los que no buscan en trasmundos un motivo para hundirse y sacrificarse, sino que se sacrifican por la tierra, para que surja en ella el superhombre" (2002: 11).

Parece que Nietzsche no comprende este evento de antropomorfización de Dios y se pelea con un Dios en el que no cree, es decir, confunde a Dios con la religión. Algo que no parece sucederle a Karl Marx, pues este más bien se dedica a realizar una crítica social e histórica a la religión y a sus deberes filantrópicos históricos no cumplidos.

La filosofía del ateísmo recala, lastimosamente, en dilemas peligrosos, y más peligrosos aún que los religiosos: convierte al ser humano en un ser materialista y en un arrogante intelectual. El racionalismo ateo clásico, el irracionalismo ateo nietzscheano y posmoderno, por lo tanto, son también especulaciones que rayan en el absolutismo religioso de la negatividad, y con esto absolutizan el poder de conciencia en el ser humano, al liberarlo de la denominada domesticación religiosa, pero esclavizándolo de su contradictoria negación y odio de lo absoluto, lo que convierte su discurso en un nuevo absoluto, una nueva religión. Se trata del advenimiento del ser humano adorado por sí mismo y desde sí mismo; el egoísmo humano se reivindica en cuanto ya el ser humano no necesita más de Dios, o de la religión. Se bastará a sí mismo. Es la venida de la divinización de la humanidad. Repito: ¡una nueva religión!

\section{Cuarto enclave: la actitud psicológica del ateo}

Algunos conceptos pueden esclarecer más, a continuación, el pensamiento ateo. Rank expone al respecto que el ser humano se siente amenazado por la divinidad, le causa miedo, comparar a la religión con la magia se le llega a considerar como "enemiga de lo racional", la laicización cultural invita a dejar de "necesitar" de Dios, la negación de lo religioso en mucho se da por una real experiencia religiosa, la concepción acientífica y antihumanista de la religión producen una alienación en el ser humano, Dios es dejado de lado en los momentos del vivir o discutir el placer, "Dios decepciona" por la maldad que abunda en el mundo, la idea de "Padre" no gusta; por ende, hablar del servir a Dios y a su eventual plan, resulta humillante (1973: 226 y ss.).

Analicemos.

Rank considera que el ateísmo no es sino el resultado del temor al dominio y del eventual y real egoísmo y egocentrismo humano, lo que produce un discurso o dialéctica de la razón enfrentada al sentimiento de fe, o a su intuición. Mas no se puede obviar que el ateísmo, como cualquier otro evento histórico humano personal o social, no es sino el resultado del trauma que causa el encuentro con la maldad misma y su consecuente negación. El mal es no deseado por naturaleza, pero ante la imposibilidad humana de vencer el mal, que es evidente ontológicamente, le encarga esta solución a Dios, pero no distingue en su complejo sistema de esperanza inmediata una solución del dilema desde sí mismo, y con esto el ateo "se disgusta con la divinidad" y con todo lo que ella engloba, entiéndase la religión. Sumado esto además al disgusto y al resentimiento causado por la sociedad humana real, y evidente gestora del mal.

Pero si queremos, y es nuestra pretensión, indagar todavía mucho más en la psicología del ateísmo, es necesario definir que el ateísmo tiende al pesimismo y al escepticismo ontológico ante la cotidianeidad histórica de la humanidad. Por ende, la actitud psicológica del ateo se visualiza desde este punto. Jean Paul Sartre expresa lo siguiente: 
El existencialismo no es otra cosa que un esfuerzo por sacar todas las consecuencias de una posición atea coherente. De ninguna manera busca hundir al hombre en la desesperación [...] El existencialismo no es propiamente un ateísmo, en el sentido de que se consuma en demostrar que Dios no existe. Más bien declara: aunque Dios existiera, esto no cambiaría nada; tal es nuestro punto de vista [...] es necesario que el hombre vuelva a encontrarse a sí mismo y se convenza de que nada preciso puede salvarlo de sí mismo, así se trate de una prueba admisible de la existencia de Dios (1997: 74).

Entiendo un evidente pesimismo antropológico en Sartre, que se justifica desde la historia humana y sus atrocidades.

Nietzsche (2007) escribe: "En el primer caso, cuando los dominadores, son quienes definen el concepto de 'bueno', son los estados psíquicos elevados y orgullosos los que son sentidos como aquello que distingue y que determina la jerarquía. El hombre aristocrático separa de sí a aquellos seres en los que se expresa lo contrario de tales estados elevados y orgullosos; desprecia a esos seres" (2007: 161).

Nietzsche era elitista y selectivo -eugenésicono solo en su discurso, sino también en el trato con las personas, incluso con actitudes. Su filosofía es aristocrática, porque es pesimista.

El ateísmo es solitario porque tiende a llevar a la soledad a sus seguidores. Esto lo causan el escepticismo, el pesimismo y el odio. Tal desprecio hacia lo no ateo repercute profundamente en su estado de ánimo y ese disgusto produce un ostracismo existencial, de tal manera que lo llevan a una negatividad de la bondad humana. Aun así, el ateísmo es un realismo del humanismo ontológico e histórico.

En la negación de la metafísica, el filósofo ateo acude y se vuelve irracional, su despecho ante la religión y la divinidad no surge sino de su resentimiento existencial y vivencial.

Incluso la tal buscada libertad en Nietzsche no es sino el producto de un deseo sentimental por obtener la emancipación de la moral, pero cuando descubre que el ser humano se mantiene en el mundo religioso se enoja y refunfuña, y solicita un cambio existencial y vivencial, que lo guía a la negación absoluta de la fe. ¡Teniendo él fe! es más pesimista.

Es decir, existe un marcado sentimiento y emoción como acicates del ateísmo teórico y práctico, aunque en el ateísmo clásico se asegure su racionalismo. Ya en el ateísmo posmoderno la esencia es evidentemente irracional, y hasta conveniente. La tragedia demarcada en el pensamiento ateo no es sino la interpretación de la realidad humana, la decepción de la historicidad de lo humano y sus consecuencias destructivas: ¡el ateísmo es un pesimismo!, la esperanza se desvanece, porque la búsqueda incesante de la libertad deviene inevitablemente en la realidad de su imposibilidad, y eso afecta el ánimo, más que a la razón.

Ante el absoluto escepticismo, la divinidad proporciona una esperanza metafísica de fe, exista Dios o no exista.

Celedonio Ramírez escribe, refiriéndose a Nietzsche: "Para Nietzsche, la muerte de Dios es un evento histórico que es condición indispensable para reencontrarnos y lograr un verdadero humanismo" (1999: 93). El humanismo psicológico presentado por Nietzsche deviene en una contradicción o bien en una interpretación fundamentada en la liberación magistral y total de lo religioso. El mismo Ramírez escribe: "Al abandonar a Dios, Nietzsche se queda con un mundo sin límites, sin dirección, sin ancla y sin significado" (1999: 103).

Erradicar la idea de Dios de la mente humana es imposible, luchar contra ella es suicidio existencial y negarla es ateísmo.

Evitar a Dios es imposible. Si concebirlo nos turba, psíquicamente es más doloroso encontrarse con una realidad epistemológica que nos atañe diariamente y no nos deja en paz. Solo Dios tiende a generar esperanza al ser humano (incluso cuando lo antropomorfiza), y sin esta la vida pierde significado.

Ramírez también trata el pensamiento de Albert Camus, quien interpreta que el ser humano está determinado por la conciencia de muerte, que es real y no una ficción. Afirma Ramírez: "Por una parte, existe un deseo joven de vivir, el cual es como una llama viva en el hombre, y al 
mismo tiempo existe la certeza absoluta de una muerte inescapable" (1999: 239).

\section{Quinto enclave: psicología del ateísmo y las tentaciones hacia él}

Por su parte, Godin (1973) explica que hay cinco rasgos o actitudes religiosas en la realidad psíquica de cada ser humano y que afectan su conducta:

1. El antropomorfismo, que es "la tendencia a representar a Dios como un personaje humano, atribuyéndole formas, rasgos de carácter o actividades humanas". Godin cita dos tipos de antropomorfismo: el imaginario, como la creación de una imagen de Dios prolongada en el mundo y que puede ser de características materiales, espirituales o intermedias, y el afectivo, que consiste en un cúmulo de actitudes que parten de las relaciones sociales humanas, familiares y de la primera infancia, que van a determinar la comprensión y actitud ante lo religioso.

2. El animismo, es decir, una "propersión a dotar de intenciones al universo inanimado y al mundo de los seres vivientes", dotar a la naturaleza de carácter divino, o lo que Godin determina en dos tipos de animismo: el punitivo, es decir del castigo, en donde a partir de la experiencia y en el campo del castigo se involucra a Dios en esa circunstancia. Y el protector, que consiste en aquello en donde "por circunstancias fortuitas se logra salir de un apuro o dilema" y de igual manera a Dios se le involucra en lo sucedido.

3. La mentalidad mágica. Explica Godin que el ser humano busca por medio de ritos y cultos la intervención de elementos sobrenaturales, pues busca el beneplácito y favor de "los espíritus". Así la oración se convierte en "evento mágico". Esto llevaría a un evidente peligro cognitivo: caer en la superstición, con lo cual Dios se convierte en objeto "de uso" para los intereses del ser humano.
4. El moralismo. Por "la conciencia del pecado" la persona se siente indigna, luego, tiende a mirar a Dios como un ser lejano y la posibilidad de una salvación como imposible. De esta manera, al no encontrar sentido en la búsqueda de Dios decide liberarse de él, lo que en realidad es liberarse del sentimiento de culpa.

5. El psicologismo, que se da cuando los valores religiosos se transmutan en meras proyecciones de las necesidades y deseos de cada ser humano y de la humanidad en general (p. 273 ss.).

\section{Sexto enclave: el ateísmo y el psicoanálisis}

El psicoanalista es ateo porque no acepta la intervención de la fe -ni en contra ni a favor-, punto crucial en su metodología por cuanto la fe sería una influencia inconveniente contra la búsqueda de la verdad. Es ateo, pues niega racionalidad a la religión, la "verdad absoluta" está en el inconsciente que no es sino el "interlocutor" entre la realidad percibida -razonamiento consciente- y la realidad acontecida pero no percibida inmediatamente -razonamiento inconsciente-. Es decir, para el psicoanálisis, es el inconsciente el que define el carácter y temperamento de la persona, y en mucho, desde los traumas sucedidos en la vida de cada quien.

Rememorando a Sigmund Freud, en sus ideas, recordemos que él consideraba que todo relato es verdadero, pero en cuanto resultado de lo consciente e inconsciente. Pero, más aún, explica Freud que la verdad estaba en aquello "que no se decía", y esto nos resulta altamente relevante para nuestro análisis, dado especialmente el caso citado.

\section{Sétimo enclave: ateísmo y cristianismo}

Para el ateo, Dios es ontológicamente innecesario, pero psicológicamente todo lo contrario. Sin Dios el ateísmo es irreal, ¡no tendría sentido!, no existiría. La autosuficiencia promulgada por el ateísmo no es real, solo aparente, ¡falaz!

Psicológica y epistemológicamente el ateísmo es una negación del concepto de Dios, pero no de la religión. Al contrario, la fundamenta y 
le da valor, pero con ello le da valor a Dios. El ateísmo está íntimamente ligado al cristianismo, e históricamente son inseparables, pues en ambos el ser humano tiende a ser Dios, se convierte en Dios. En el cristianismo a partir de la antropomorfización de Dios y una cuasidivinización de sus autoridades, en el ateísmo por la necesidad de creer en la sacralidad del ser humano. Y ambos son paganos. Al respecto Sciacca escribe: "el cristianismo es un ateísmo del teísmo romano y un ateísmo del teísmo judío" (1963: 137).

Dentro del análisis católico acerca del origen psicológico del ateísmo, el sacerdote Félix Moracho (1973) explica que para "pasar a ser un ateo" hay varios caminos, los cuales pueden mencionarse de esta manera: las situaciones infrahumanas de miseria, el mal y el sufrimiento; el dilema de lo que nos dice la razón: "un Dios que puede, pero que no quiere evitar el mal", "un Dios que quiere, pero que no puede evitar el mal"; el ambiente de indiferencia, el trabajo y las ocupaciones absorbentes; la riqueza; "cuando el traje de primera comunión se queda corto"; cuando el conocimiento científico es lo único que vale.

A esto suma el sacerdote tres particulares fabricantes de ateos: el descuido de la educación religiosa, la exposición inadecuada de la doctrina y los mismos defectos de la vida religiosa, moral y social que han velado, más que revelado, el genuino rostro de Dios y de la religión (pp. 83-84).

\section{Algunas conclusiones}

A continuación presento algunas conclusiones a este sintético discurso a modo de corolario.

1. El ateísmo negativo es el reemplazo de la idea de Dios por el vacío; el ateísmo positivo es un antiteísmo.

2. Solo pensar en Dios provee de existencia al ateísmo, aunque sea solo psicológicamente.

3. El ateísmo absoluto es el intento de negación de Dios ontológicamente; el ateísmo relativo en cuanto lo que se conciba como Dios.
4. El ateísmo práctico es producto de un ateísmo teórico, nacido de la irracionalidad atea y significa "vivir como si Dios no existiese".

5. La psicología del ateísmo es correlativa a la psicología de la religión.

6. La negación de Dios más que psicológica es ideológica.

7. El ateísmo es producto de procesos psicológicos tales como el miedo, la desconfianza, la desaprobación, el resentimiento o el disgusto.

8. Las raíces psicológicas del ateísmo pueden comprenderse como el antropomorfismo, el animismo, la mentalidad mágica o el moralismo.

9. La historia misma puede fundamentar la psique de la persona para definir su ateísmo, a través de la experiencia de miseria, sufrimiento, mal, racionalidad, indiferencia, ciencia, riqueza o trabajo.

10.El cristianismo mismo y su mal ejemplo proveen de fundamentos ideológicos al ateísmo.

\section{Un esbozo final: una breve referencia a Miguel de Unamuno}

En su libro La agonía del cristianismo (1966) Miguel de Unamuno acuña algunas ideas que creo muy importantes para esta reflexión.

Parafraseando al filósofo vasco, podemos considerar que el error nietzscheano estuvo en definir el cristianismo como un evento social, cuando en realidad es un evento individual, si lo entendemos como la vivencia particular del Cristo.

Unamuno prefiere hablar de cristiandad, ya que el cristianismo es un concepto politizado e institucionalizado, lo cual no era el propósito de Cristo. El cristianismo, al convertirse en religión, fue transgredido en su esencialidad, pues la cristiandad es una vivencia personal del amor expreso de Dios a través de la persona de su hijo Jesucristo. 
El catolicismo y el protestantismo se han convertido en el emblema y estandarte occidental de Dios en la Tierra, aunque Dios no sea ni religión ni política; mucho menos una institución.

¡No es Nietzsche quien mata a Dios, es la religión!

Unamuno escribe: "y no creer es creer" (1966: 68). La fe y la religión son inevitables, tanto como Dios, pero no son lo mismo. El ateísmo es inevitable también, psicológicamente, pero sí es religión.

\section{Bibliografía}

Godin, A. (1973). "Desarrollo psicológico y tentación del ateísmo”. En: G. Girardi. El ateísmo contemporáneo, Vol. I, Tomo I. Madrid: Ediciones Cristiandad: 273-289.

Moracho, F. (1992). Los diez mandamientos. Colombia: Ediciones Paulinas.
Muñoz, A. (1972). Dios, ateísmo y fe. Salamanca, España: Ediciones Sígueme.

Nietzsche, F. (2002). Asi hablaba Zaratustra. México: Editores Unidos Mexicanos.

Nietzsche, F. (2007). Más allá del bien y del mal. Buenos Aires: Gradifco.

Ramírez, C. (1999). Preparando el regreso a lo real. Introducción a cinco pensadores existencialistas. San José: Euned.

SARTre, J.P. (1997). El existencialismo es un humanismo. San José: Editorial Guayacán Centroamericana.

Sciacca, M. (1963). Existencia de Dios y ateísmo. Buenos Aires: Editorial Troquel.

Unamuno, M. (1966). La agonía del cristianismo. Madrid: Colección Austral.

Unamuno, M. (2004). Del sentimiento trágico de la vida. Buenos Aires: Longseller. Colección Clásicos de Siempre, Grandes Filósofos. 